\title{
Relief supply in the aftermath of the 2009 typhoon morakot
}

\author{
Yen-Hsiung Liao \\ Department of Health Sciences, School of Public Health, Kaohsiung Medical University \\ *Corresponding author E-mail: bany0309@yahoo.com.tw
}

\begin{abstract}
Purpose: To monitor whether the relief including food, and supplies met the need for the Typhoon Morakot victims. Approach: Relief data was obtained from the Relief Coordination Center (RCC), Pingtung County Government during July 10 to July 28,2009 . The relief was classified into food and supplies categories.

Results: The most need of relief was cleaner necessaries $(8 / 15=53.3 \%)$, the last need of relief was seasoning $(0 / 15=0 \%)$. The subjects including eggs, bread, cloths, socks, lighter, and candle were not required by the victims although they were donated by people.

Conclusion: The several catchment areas in Pingtung County needed to be cleaned after the flooding. Therefore, the kind of cleaner necessaries was the most as well as the longest need of relief expectantly. Our results suggest the priorities of resources allocation for the next disaster.
\end{abstract}

Keywords: Typhoon Morakot, Cleaner Necessaries, Resource Allocation.

\section{Introduction}

On August 8th, 2009, Typhoon Morakot brought extreme rainfall and resulted in flooding which shocked the world and devastated southern Taiwan. The natural disaster resulted in enormous losses to people's homes, land, assets, and lives. After the disaster, governmental agencies, military, and private organizations immediately involved in disaster relief efforts. Two days after, with great efficiency the government established the Relief Coordination Center (RCC) that responded in the allocation of relief to the affected areas every day from August 10 to August 28, 2009.

To deliver relief to affected communities effectively, the adequate assessment of relief supplies is very important.The aim of this study is to monitor whether the relief including food, and supplies met the need for the Typhoon Morakot victims.

\section{Methods}

Post -typhoon relief data was obtained from the Relief Coordination Center (RCC), Pingtung County Government. The relief was classified into food and supplies categories that adopted from the National Fire Agency, Ministry of the Interior.

The food included 6 kinds, such as rice and noodle (rice, instant noodle, ground rice, noodle, flour, egg), seasoning (oil, salt, soya sauce, mono sodium glutamate, sugar), dried food (bread, cookies), packaged and canned food, milk powder, and beverage and water.

The supplies included 6 kinds, such as bedding and pillow (bedquilt, sleeping bag, camp, blanket, sleeping pad, mosquito net, trash bag, slipper), article for daily use (tube, toilet paper, shampoo, towel, toothbrush, tooth paste, soap), cleaner necessaries (antiseptic, mask, gloves, broom, brush, grabber, shovel, mop), dresses (cloths, socks, raincoat, rain shoes), infant materials, and light ( battery, flashlight, lighter, candle).

During July 10 to July 28, 2009, the time was divided into 3 periods by five day interval including the first period (July 10 - July 14, 2009), the second period (July15 - July20,2009), the last period (July21- July28,2009). There were no registered data in July 19, July 23, July 25, and July 27.

\section{Results}

Table 1 and table 2 show the need of food and supplies aftermath of the 2009 Typhoon Morakot. The most need of relief registered by the RCC was cleaner necessaries $(8 / 15=53.3 \%)$, the last need of relief was seasoning $(0 / 15=0 \%)$. The major need of food was rice and noodle $(7 / 15=46.7 \%)$, and beverage and water $(7 / 15=$ $46.7 \%)$ respectively. The major need of supplies was cleaner necessaries $(8 / 15=53.3 \%)$, followed by article for daily use $(7 / 15$ $=46.7 \%)$. The least need of food and supplies was seasoning $(0 / 15$ $=0 \%)$, and infant materials $(1 / 15=6.7 \%)$ respectively.

The need of relief declined sharply in the last period, except the need of article for daily use, and cleaner necessaries. The major need was rice and noodle, and beverage and water in the first period respectively $(3 / 5=60.0 \%)$. The major need was rice and noodle, dried food, beverage and water, article for daily use, and cleaner necessaries in the second period respectively $(3 / 5=60.0$ $\%)$. The major need of relief was article for daily use, and cleaner necessaries in the last period respectively $(3 / 5=60.0 \%)$.

A large subjects of relief (egg, oil, salt, soya sauce, bread, cloths, socks, lighter, and candle) donated by people were delivered without any requirement or coordination to the RCC, which caused significant difficulties in storage, transporting, and other emergency services. 
Table 1: Need of food registered by the Relief Coordination Center.

\begin{tabular}{llllll}
\hline Food & rice and noodle & seasoning & dried food & \multicolumn{2}{c}{ packaged and canned } \\
food & milk powder & \\
Period & & & & $0 / 5$ & $2 / 5$ \\
1 & $3 / 5$ & $0 / 5$ & $1 / 5$ & $1 / 5$ & $0 / 5$ \\
2 & $3 / 5$ & $0 / 5$ & $1 / 5$ & $0 / 5$ & $3 / 5$ \\
3 & $1 / 5$ & $0 / 5$ & $1 / 5$ & $1 / 5$ \\
Total & $7 / 15$ & $0 / 15$ & $5 / 15$ & $1 / 15$ & $2 / 15$ \\
\hline
\end{tabular}

Period 2: July15 - July20, 2009 (except July 19, 2009). Period 3: July21- July28, 2009 (except July 23, July 25, and July 27).

Table 2: Need of supplies registered by the Relief Coordination Center.

\begin{tabular}{|c|c|c|c|c|c|c|}
\hline Supplies & bedding \& pillow & $\begin{array}{l}\text { article for daily } \\
\text { use }\end{array}$ & cleaner necessaries & dresses & infant materials & light \\
\hline \multicolumn{7}{|l|}{ Period } \\
\hline 1 & $2 / 5$ & $1 / 5$ & $2 / 5$ & $1 / 5$ & $1 / 5$ & $2 / 5$ \\
\hline 2 & $1 / 5$ & $3 / 5$ & $3 / 5$ & $2 / 5$ & $0 / 5$ & $2 / 5$ \\
\hline 3 & $0 / 5$ & $3 / 5$ & $3 / 5$ & $0 / 5$ & $0 / 5$ & $0 / 5$ \\
\hline Total & $3 / 15$ & $7 / 15$ & $8 / 15$ & $3 / 15$ & $1 / 15$ & $4 / 15$ \\
\hline
\end{tabular}

\section{Discussion}

Disaster preparedness contribution to disaster reduction (Deitchman 2005, p.3; Blame 2012, p.8).This study suggested action strategy for relief preparedness and response of typhoon. According to the RCC organization, relief supplies reached victims within days, as opposed to weeks in previous years, thereby preventing further loss of life, and illness, as well as augmenting the efficiency of resource use.

After Morakot landed in the midnight of August 8, almost the entire southern region of Taiwan was flooded by record-breaking heavy rain. The several catchment areas in Pingtung County needed to be cleaned after the flooding. Therefore, the kind of cleaner necessaries was the most need of relief expectantly. Our results suggest the priorities of resources allocation for the next disaster. Seasonig was the last need of relief, because many volunteers cooked for them when they lived in the shelters. The subjects of relief

Such as eggs, bread, cloths, socks, lighter, and candle was not required by the victims. Benini et al suggested the deliver relief to affected communities be more completely and coherently (Benini et al 2009, p.22). Our results suggest the priorities of resources allocation for the next typhoon and flooding.

\section{Acknowledgements}

This work was supported by the Pingtung County Government.

\section{References}

[1] Deitchman S (2005). What have we learned? - needs assessment. Prehosp Disast Med 20, 468-470.

[2] Benini A, Conley C, Dittemore B \& Waksman Z (2009). Survivor needs or logistical convenience? Factors shaping decisions to deliver relief to earthquake-affected communities, Parkistan 2005-06. Disasters 33, 110-131.

[3] Bame SH, Parker K, Lee JY, Norman A, Finley D, Desai A, Grover A, Payne C, Garza A, Shaw A, Bell-Shaw R, Davis T, Harrison E, Dunn R, Mhatre P, Shaw F \& Robinson C (2012), Monitoring unmet needs using 2-1-1 during nature disasters. Am J Prev Med 43, s435-s442. 